\title{
ELABORAÇÃO DE BISCOITOS TIPO COOKIE COM FARINHA DE RESÍDUOS DO PROCESSAMENTO DE EXTRATO DE YACON
}

\author{
T. S. GOES ${ }^{1}$, A.P. DIONÍSIO ${ }^{2}$, A. L. G. MODESTO ${ }^{2}$, I. M. S. ARAÚJO ${ }^{2}$, D. F. PONTES ${ }^{1}$, R. P. \\ OLIVEIRA $^{1}$, C.C. CRISÓSTOMO ${ }^{1}$ \\ ${ }^{1}$ Universidade Federal do Ceará, Departamento de Tecnologia de Alimentos \\ ${ }^{2}$ Embrapa Agroindústria Tropical - CNPAT/EMBRAPA \\ E-mail para contato: rayannepoliveira@outlook.com
}

\begin{abstract}
RESUMO - O resíduo sólido do processamento do extrato de yacon (Smallanthus sonchifolius) apresenta ainda concentrações consideráveis de prebióticos do tipo frutooligossacarideos (FOS). Desta forma, este trabalho teve como objetivos elaborar e avaliar biscoitos tipo "cookie" formulados com diferentes concentrações deste resíduo, em substituição parcial ou total da farinha de trigo. O resíduo foi processado originando a farinha de yacon (FY), que foi usada na elaboração das diferentes formulações (A1=0\%, $\mathrm{A} 2=50 \%$ e $\mathrm{A} 3=100 \% \mathrm{FY})$ para avaliação sensorial $(\mathrm{n}=48)$. Os atributos avaliados foram: aparência, sabor, doçura, aceitação global e a atitude de compra. Concluímos que A1 e A2 foram as mais aceitas pelos consumidores, e A3 foi a menos aceita, apresentando os mais baixos índices em todos os atributos. Logo, há possibilidade de incorporação da farinha junto ao cookie, o que é interessante pelo ponto de vista nutricional, e também de aproveitamento integral de um produto de elevado valor agregado.
\end{abstract}

\section{INTRODUÇÃO}

O yacon (Smallanthus sonchifolius) é uma planta perene originária dos Andes, pertencente a família Astraceae. As raízes do yacon são tuberosas, similares à batata doce em aparência, com um gosto normalmente doce por apresentar abundância de carboidratos solúveis tais como frutose, glicose, sacarose e fruto-oligossacarídeos ou inulina, entretanto com nível energético relativamente baixo (Cazetta et al., 2005).

Tais características tornam versátil a utilização do yacon, com fácil incorporação em produtos alimentícios. Apesar de o yacon ser comumente consumido in natura, diversos produtos tem sido desenvolvidos com o intuito de explorar as potencialidades desse alimento, devido ao fato principal de apresentar elevadas concentrações de frutooligossacarideos (FOS). O percentual de FOS encontrado no yacon encontra-se em torno de 40 e $70 \%$ dos carboidratos, os quais são também chamados de açúcares não convencionais com amplo impacto na indústria do açúcar em razão das suas excelentes características funcionais em alimentos, além de seus aspectos fisiológicos e físicos (Spiegel et al., 1994). 
Considerando o amplo espectro de aplicações de yacon, a sua incorporação em "bebidas funcionais" torna-se interessante devido ao seu sabor adocicado, semelhante a frutas como pêra. Porém, seu processamento gera um resíduo de elevado valor nutricional, até então, pouco explorado. Desta forma, utilizar este resíduo em outros produtos, como cookies, torna-se uma importante estratégia de mercado, com aproveitamento integral dos produtos e sub-produtos gerados no processamento da raiz tuberosa, ampliando o leque de aplicações de yacon na área de "alimentos funcionais".

As mudanças no processamento e a crescente exigência do consumidor por alimentos que apresentem, além da alta qualidade sensorial e nutricional, benefícios associados à saúde, fazem surgir a necessidade de novos ingredientes que possam atender a estas exigências do mercado (Hauly et al., 2004).

Embora não constitua um alimento básico como o pão, os biscoitos são aceitos e consumidos por pessoas de qualquer idade. Sua longa vida de prateleira permite que seja produzidos em grande quantidade e largamente distribuídos (Chang et al., 1998).

Os biscoitos tipo cookie, recentemente, têm sido formulados com a intenção de implementar sua fortificação com fibra ou proteína, devido ao forte apelo nutricional que existe hoje em dia com relação aos alimentos consumidos. Entretanto, para que uma tecnologia adequada seja desenvolvida, é necessário que os alimentos escolhidos para formulação de farinhas compostas sejam pesquisados em relação a composição química, características físicas e nutricionais. Também deve-se considerar que o processo de desenvolvimento e otimização do produto final envolva a realização de testes sensoriais afetivos (de consumidores) de forma a se elaborar formulações competitivas e de grande aceitação (Chang et al.,1998).

O cookie vem conquistando vários consumidores e a sua comercialização vem aumentando muito no pais devido sua fácil preparação por ser leve e prático, entretanto as indústrias estão tendo a preocupação de desenvolver formulações que agradem o paladar e ainda tenha propriedades funcionais, já que a população está mais exigente e preocupado com a saúde.

Desta forma, este trabalho tem como objetivo elaborar cookies com a substituição da farinha de trigo pela farinha de yacon e analisar sensorialmente essas preparações elaboradas.

\section{METODOLOGIA}

\subsection{Farinha de yacon}

A farinha de yacon obtida a partir de raízes tuberosas de yacon descascadas, secas e trituradas.

A produção de farinha de yacon seguiu as etapas de procedimento estabelecido no fluxograma da Figura 1. 


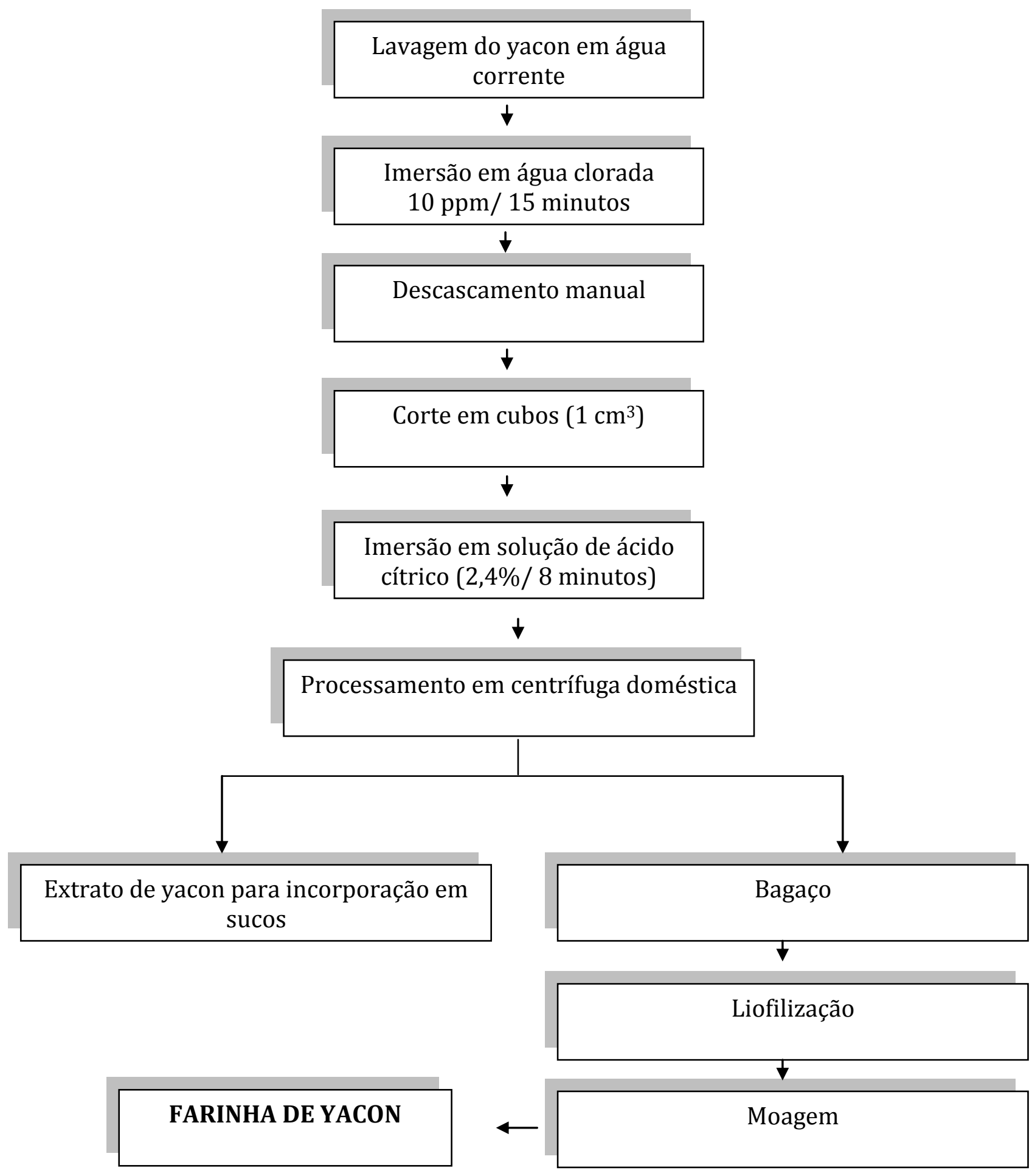

Figura 1 - Fluxograma do processo de farinha de yacon. 


\subsection{Formulações para os cookies}

Na produção dos biscoitos, utilizaram-se: i) ingredientes: farinha de trigo, stevia (1g), margarina ligth (100 gramas), ovo (1 unidade), fermento em pó (1 grama), achocolatado ligth (45 gramas) e farinha de yacon; e ii) material: utensílios empregados no preparo de alimentos, como vasilhas plásticas, colheres e espátulas, entre outros. Nos testes de análise sensorial, foram usados materiais descartáveis como copos, bandejas e guardanapos.

Os ingredientes das formulações (A1) para os cookies foi $100 \%$ de farinha de trigo (120 gramas), formulação (A2) contendo a 50\% farinha de yacon e 50\% de farinha de trigo (60 gramas de cada uma das farinhas) e a formulação (A3) contendo 100\% de farinha de yacon (120 gramas).

\subsection{Avaliação sensorial}

Os testes de aceitação dos cookies foram realizados utilizando-se a escala hedônica estruturada de 9 pontos ( $1=$ Desgostei muitíssimo; 5=Nem gostei/Nem desgostei; 9=Gostei muitíssimo), para avaliar os atributos aparência, sabor, doçura, aceitação global e atitude de compra (5=certamente compraria, $3=$ talvez comprasse/talvez não comprasse e 1=certamente não compraria). Participaram 48 provadores não treinados que receberam as amostras simultaneamente, codificadas com 3 dígitos e em ordem casualizada.

\section{RESULTADO E DISCUSSÃO}

Os resultados da aceitação sensorial das diferentes formulações estão apresentados na Tabela 1.

Tabela 1 - Aceitação das amostras

\begin{tabular}{|c|c|c|c|c|}
\hline Amostra & Aparência & Aceitação Global & Aceitação Sabor & Aceitação Doçura \\
\hline A1 & $6,19^{\mathrm{a}}$ & $6,00^{\mathrm{a}}$ & $6,00^{\mathrm{a}}$ & $6,15^{\mathrm{b}}$ \\
\hline A2 & $6,00 \mathrm{a}$ & $5,90^{\mathrm{a}}$ & $6,25^{\mathrm{a}}$ & $6,94^{\mathrm{a}}$ \\
\hline A3 & $5,35^{\mathrm{a}}$ & $5,35^{\mathrm{a}}$ & $5,40^{\mathrm{a}}$ & $5,81^{\mathrm{b}}$ \\
\hline
\end{tabular}

Análise de variância pelo teste de Tukey ao nível de significância de 5\%. 
O aspecto visual, no atributo aparência, a amostra A1 foi a que apresentou a maior nota, porém não foi estatisticamente significativa das demais amostras que continham variáveis concentrações de farinha de yacon. Algumas amostras apresentarem-se "queimadas" e isso pode ter interferido nos valores obtidos no presente trabalho.

Para o atributo sabor, a amostra melhor pontuada dentro da região de aceitação foi a A1, seguida das amostras A2 e A3. Para o sabor, as amostras seguiram a mesma ordenação. Porém, em ambos os casos as amostras não apresentaram diferenças estatísticas entre si.

Como as amostras são destinadas para um público específico, que consome produtos diet e light, foi utilizada nas formulações achocolatado em pó light e stévia como edulcorante. Devido a este fato, foi importante avaliar o termo "doçura" das amostras. Para este atributo, foi observado que a amostra A2 foi a que apresentou melhores notas, seguidas pelas amostras A1 e A3. A amostra A2 foi a única que apresentou diferença estatística quando comparada as demais amostras.

Para aceitação global, a amostra A1 foi a que obteve o melhor percentual ( 78\%) dentro da área de aceitação (correspondente ao somatório das notas entre 6 e 9). As demais amostras apresentaram valores muito próximos de aceitação hedônica, sendo eles, 62\% (Amostra A2) e 66\% (Amostra A3). Porém, como pode ser visualizada na Figura 2, a amostra A2 apresentou uma frequência maior em notas superiores, assim como uma maior média (Tabela 1). 

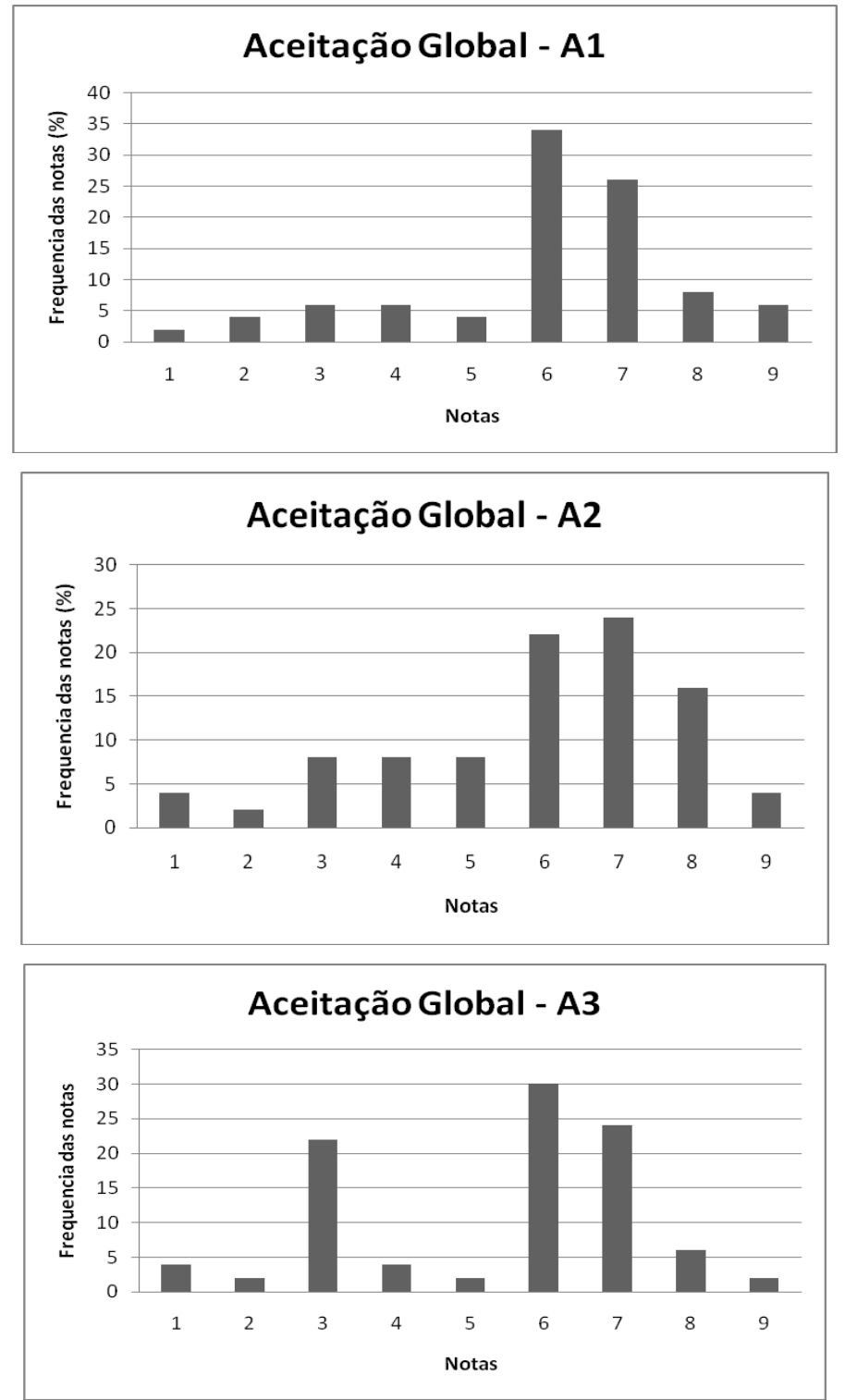

Figura 2 - Histograma de frequência de notas para o quesito aceitação global par as três diferentes formulações (A1, A2 e A3). 


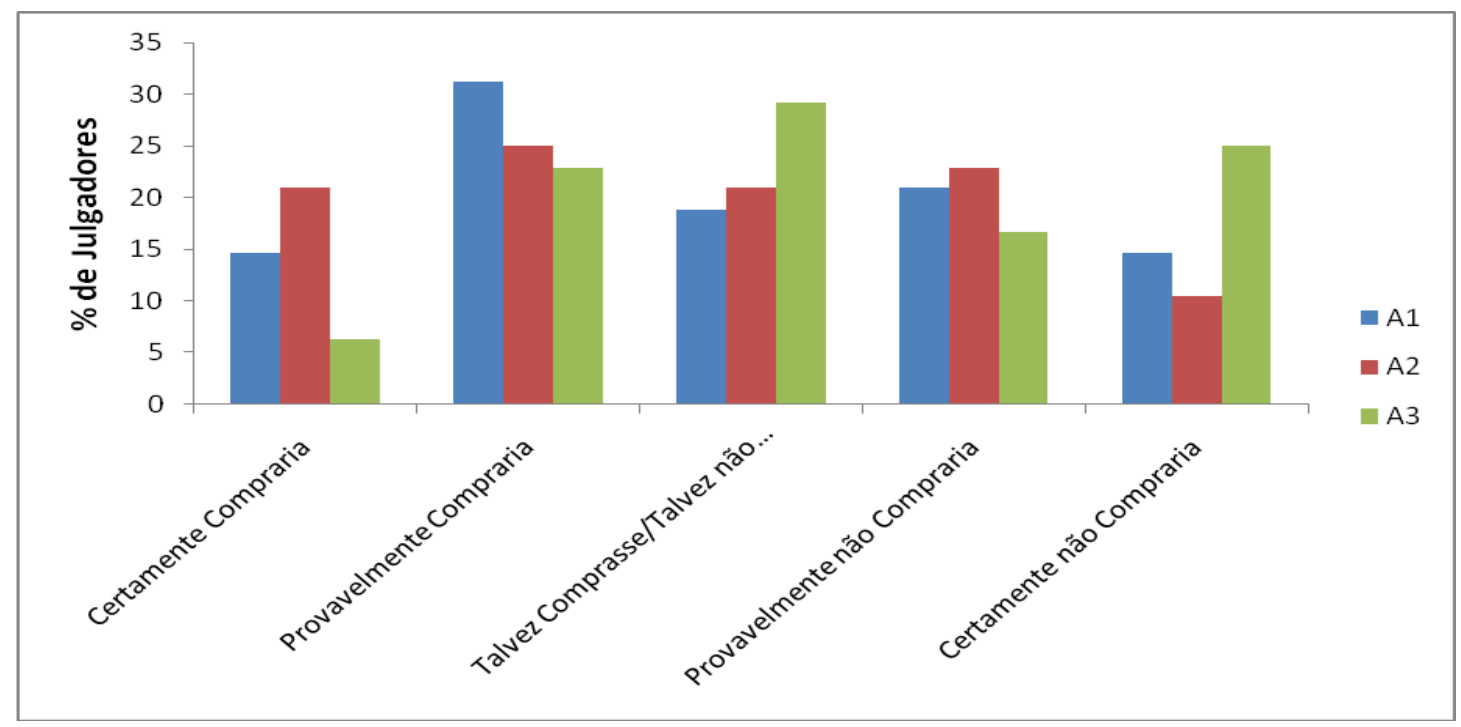

Figura 3 - Histograma de percentual de julgadores no quesito intenção de compra

Para "intenção de compra" (Figura 3), observa-se que a amostra A3 foi a que apresentou maior índice de rejeição, com maiores percentuais para a nota 1 (25\% "certamente não compraria"), visto que já era esperado este resultado pelo fato de ter obtido um índice inferior na aceitação global em relação às demais amostras. Por sua vez, a amostra A2 apresentou o menor índice de intenção de compra, com percentuais de 10,4\%, seguida da amostra A1 com percentuais de $14,6 \%$ para a mesma nota. O quesito intenção de compra pode ser relacionado com a aceitação global, visto que a amostra A2 é tão aceita quanto a amostra A1 pelos consumidores (notas 5,9 e 6,0 , respectivamente); porém a amostra A2 foi a que obteve a maior nota para intenção de compra.

\section{CONCLUSÃO}

De acordo com os atributos avaliados aparência, sabor, aceitação global e atitude de compra, concluímos que foram as amostras A1 (contendo somente farinha de trigo) e A2 (contendo 50\% de farinha de yacon) foram as mais aceitas pelos consumidores. A amostra A3 (contendo somente 100\% de farinha de yacon) foi a menos aceita pelos consumidores, apresentando os mais baixos índices em todos os atributos e quesitos avaliados. Desta forma, podemos concluir que há possibilidade de incorporar ao produto avaliado (cookie) a farinha de yacon, que é um "resíduo" do processamento do extrato de yacon. O uso da farinha de yacon em produtos processados é uma forma de incorporar compostos que trazem benefícios a saúde do consumidor (fruto-oligossacarídeos), além de gerar menos resíduos e consequentemente, mais lucro, no processamento desta raiz tuberosa. 


\section{REFERÊNCIAS}

CAZETTA, M.I.; MARTINS, P. M. M.; MONTI, R.; CONTIERO, J. Yacon (Polymnia sonchifolia) extract as a substrate to produce inulinase by Kluyveromyces marxianus var. bulgaricus. Journal of Food Engineering, v. 66, p.301-305, 2005.

CHANG, Y. K.; SILVA, M. R.; SILVA, M. A. A. P. Utilização da farinha de jatobá (Hymenaea stigonocarpa Mart.) na elaboração de biscoitos tipo cookie e avaliação de aceitação por testes sensoriais afetivos univariados e multivariados. Ciência Tecnologia de Alimentos, v.18, 1998.

HAULY, M. C. O.; PRUDÊNCIA-FERREIRA, S. H.; MOSCATO, J. A. Farinha de yacon e inulina como ingrediente na formulação de bolo de chocolate. Ciência Tecnologia de Alimentos, v. 24, p. 634-640, 2004.

SPIEGEL, J. E.; ROSE, R.; FRANKOS, V. H.; SCHMIDT, D. F. Safety and benefits of frutooligosaccharides. Food Technology, v. 48, p. 85-89, 1994. 